\title{
Efektivitas Model Pembelajaran Inkuiri dalam Meningkatkan Hasil Belajar Siswa Kelas IV SDN 27 Tegineneng
}

\author{
${ }^{*}$ Ahmad Tohir ${ }^{1}$, Ali Mashari² \\ ${ }^{12}$ Program Studi PGSD STKIP Al Islam Tunas Bangsa, Labuhanratu Bandar Lampung, Indonesia
}

\author{
A R T I C L E I N F O \\ Article history: \\ 25 December 2019 \\ Received in revised form \\ 01 January 2020 \\ Accepted 25 January 2020 \\ Available online 28 \\ February 2020 \\ Kata Kunci: \\ Efektivitas, Hasil Belajar, \\ Pembelajaran Inkuiri \\ Keywords: \\ Effectiveness, learning \\ outcomes, inquiry \\ learning
}

\begin{abstract}
A B S T RA K
Dalam proses pembelajaran didalam kelas, kadang model pembelajaran yang digunakan oleh guru di dalam kelas kurang sesuai dengan materi yang diajarkan. Hal ini dapat menyebabkan siswa menjadi kurang termotivasi dalam pembelajaran.Salah satu model yang dapat digunakan sebagai alternative adalah model pembelajaran inkuiri. Model Pembelajaran Inkuiri merupakan suatu pembelajaran berbasis permasalahan atau investigasi yang dilakukan dengan mencari kebenaran atau pengetahuan yang memerlukan pikiran kritis, kreatif serta dapat menggunakan intuisi. Penelitian ini bertujuan untuk mengetahui efektivitas model pembelajaran inkuiri dalam meningkatkan hasil belajar siswa kelas IV SDN 27 Tegineneng. Metode yang akan digunakan dalam penelitian ini adalah metode penelitian eksperimen semu (Quasi experiment). Desain yang digunakan adalah one group pretest and posttest design. Populasi dalam penelitian ini adalah seluruh siswa kelas IV SDN 27 Tegineneng. Sedangkan sampel penelitian ini berjumlah 20 siswa kelas IV SDN 27 Tegineneng. Penelitian ini akan menguji
\end{abstract} pretes dan postes. Perbedaan nilai antara pretes dan postes melalui uji Wilcoxon Matched Pairs Test. Dalam pelaksanaan uji Wilcoxon untuk menganalisis kedua data yang berpasangan tersebut dilakukan dengan menggunakan analisis uji melalui program SPSS versi16. Berdasarkan penelitian dan pembahasan dapat disimpulkan bahwa model pembelajaran inkuiri efektif dalam meningkatkan hasil belajar siswa kelas IV SDN 27 Tegineneng. Hal ini dibuktikan dari hasil Uji Wilcoxon bahwa Asymp.Sig.(2-tailed) adalah 0.000 0.05.

\begin{abstract}
A B S T RA C T
Sometimes the learning model used by the teacher on the learning process in the classroom is not appropriate with the material being taught. This problem can cause students to be less motivated in learning. One model that can be used as an alternative is inquiry learning model. The inquiry learning model is a problem-based learning or investigation carried out by searching for the truth or knowledge that requires critical, creative thinking and can use intuition. This research aimed to determine the effectiveness of the learning model of inquiry to the learning outcomes on fourth grade students at SDN 27 Tegineneng. The method used in this research was a pseudo experimental research (quasi experiment). The research design used one group pretests and posttest design. The population in this research was all fourth grade elementary students of SDN 27 Tegineneng. Meanwhile, the sample was 20 students of grade IV SDN 27 Tegineneng. This research was pretest and postest group design. The different value between pretest and postes was through the Wilcoxon Matched Pairs test. The implementation of Wilcoxon's test was to analyze both of the paired data through the test analysis by the used of SPSS 16 program. Based on research and discussion, it could be concluded that the learning model of inquiry was effective towarded with the learning outcomes on fourth grade students of SDN 27 Tegineneng. It showed by Wilcoxon's test results that Asymp. Sig. (2-tailed) was a $0.000<$ 0.05 .
\end{abstract}

\section{Pendahuluan}


Dunia pendidikan tidak lepas dari bagaimana meningkatkan hasil belajar siswa. Hal ini terus berlanjut agar generasi penerus dapat tumbuh dan memiliki daya saing. Pendidikan menjadi salah satu hal penting dan turut berperan dalam kehidupan manusia. Pendidikan mengajarkan manusia untuk tahu dan memanfaatkan sumber daya secara maksimal sehingga mampu untuk bertahan hidup. Pendidikan adalah usaha sadar dan terencana untuk mewujudkan proses pembelajaran secara aktif agar peserta didik dapat mengembangkan potensi dirinya. Tujuan pendidikan berdasarkan atas pancasila mempunyai tujuan untuk meningkatkan ketakwaan terhadap Tuhan Yang Maha Esa, kecerdasan, keterampilan, mempertinggi budi pekerti, memperkuat kepribadian agar dapat membangun diri sendiri serta bersamasama bertanggung jawab atas pembangunan bangsa.

Belajar merupakan proses perubahan tingkah laku untuk memperoleh sesuatu yang baru, sebagai hasil pengelaman individu itu sendiri dalam interaksinya dengan lingkungan (Yudhawati dan Haryanto, 2011:15). Menurut Dimyati dan Mudjiono (2013: 7) belajar merupakan tindakan dan perilaku yang kompleks. Sebagai tindakan, maka belajar hanya dialami oleh siswa sendiri. Siswa adalah penentu terjadinya atau tidak terjadinya proses belajar. Menurut Sardiman (2014: 23) belajar merupakan perubahan tingkah laku, dan terjadi karena hasil pengalaman. Sejalan dengan itu, Iskandar (2012: 102) mengatakan belajar merupakan usaha yang dilakukan seseorang melalui interaksi dengan lingkungannya untuk merubah perilakunya.

Sedangkan hasil belajar merupakan prestasi yang dicapai siswa dalam proses pembelajaran dengan membawa suatu perubahan dan pembentukan tingkah laku seseorang (Jihad dan Haris, 2010:14). Hasil belajar merupakan pengukuran dari penilaian kegiatan belajar atau proses belajar yang dinyatakan dalam simbol, huruf maupun kalimat yang menceritakan hasil yang sudah dicapai oleh setiap anak pada periode tertentu. Menurut Susanto (2013: 5), perubahan yang terjadi pada diri siswa, baik yang menyangkut aspek kognitif, afektif, dan psikomotor sebagai hasil dari belajar. Hasil belajar adalah hal yang berhubungan dengan kegiatan belajar karena kegiatan belajar merupakan proses dan hasil belajar adalah hasil yang dicapai seseorang setelah mengalami proses belajar dengan terlebih dahulu mengadakan evaluasi proses belajar yang dilakukan. Hasil belajar siswa adalah keberhasilan yang dicapai oleh siswa, yakni prestasi belajar siswa di sekolah yang diwujudkan dalam bentuk angka.

Berdasarkan observasi dan wawancara di SDN 27 Tegineneng diperoleh data hasil belajar siswa kelas IV tahun pelajaran 2018/2019 pada tema indahnya kebersamaan sebagaimana terlihat pada tabel 1 berikut:

Tabel 1. Hasil Belajar Siswa Kelas IV TP 2018/2019

\begin{tabular}{ll}
\hline Nama Tema & Rerata Hasil Belajar \\
\hline Indahnya Kebersamaan & 56,67 \\
Berhemat Energi & 66,67 \\
Peduli Makhluk Hidup & 68,33 \\
Berbagai Pekerjaan & 63,33 \\
Pahlawanku & 67,67 \\
\hline
\end{tabular}

Berdasarkan data di atas, dapat diketahui bahwa hasil belajar tema indahnya keberagaman memiliki rerata hasil belajar lebih rendah dibandingkan tema yang lain. Hal ini dapat dipengaruhi oleh beberapa faktor, diantaranya siswa kurang termotivasi dalam pembelajaran. Kemungkinan lain adalah model pembelajaran yang digunakan oleh guru kurang sesuai. Salah satu model pembelajaran yang dapat digunakan sebagai alternatif adalah model pembelajaran inkuiri. Model Pembelajaran Inkuiri merupakan suatu pembelajaran berbasis permasalahan atau investigasi yang dilakukan dengan mencari kebenaran atau pengetahuan yang memerlukan pikiran kritis, kreatif serta dapat menggunakan intuisi. Pembelajaran Inkuiri adalah suatu pola pembelajaran untuk membantu siswa belajar merumuskan permasalahan dan menguji pendapatnya sendiri serta memiliki kesadaran akan kemampuanya, pmbelajaran dimulai dengan pengajuan suatu masalah dan pertanyaan. Siswa dituntut untuk berpikir secara logis, analitis, dan kritis dalam mencari, menyelidiki, dan menemukan jawaban atas masalah yang dipertanyakan tersebut (Abdullah, 2013:144).

Menurut Sanjaya (2006: 195-196) pembelajaran inkuiri efektif jika seorang guru mengharapkan siswa dapat menemukan sendiri jawaban dari suatu permasalahan yang ingin dipecahkan, jika bahan pelajaran yang akan diajarkan tidak berbentuk fakta atau konsep yang sudah jadi, akan tetapi sebuah kesimpulan yang perlu pembuktian, jika proses pembelajaran berangkat dari rasa ingin tahu siswa terhadap sesuatu, jika guru akan mengajar pada sekelompok siswa yang rata-rata memiliki kemauan dan kemampuan berpikir, jika jumlah siswa yang belajar tak terlalu banyak sehingga bisa dikendalikan oleh guru, jika guru memiliki waktu yang cukup untuk menggunakan pendekatan yang berpusat pada siswa. 
Selanjutnya Trianto (2009: 115) menyatakan inkuiri merupakan bagian inti dari kegiatan pembelajaran berbasis kontekstual. Pengetahuan dan keterampilan yang diperoleh siswa diharapkan bukan hasil mengingat seperangkat fakta-fakta, tetapi hasil dari menemukan sendiri. Guru harus merancang kegiatan yang merujuk pada kegiatan menemukan, apapun materi yang diajarkannya.

Trianto (2009: 166) juga mengutip dari pendapat Gulo, model pembelajaran inkuiri merupakan suatu rangkaian kegiatan belajar yang melibatkan secara maksimal seluruh kemampuan siswa untuk mencari dan menyelidiki secara sistematis kritis, logis, analitis, sehingga mereka dapat merumuskan sendiri penemuannya dengan penuh percaya diri. Sasaran utama kegiatan pembelajaran inkuiri adalah keterlibatan siswa secara maksimal dalam proses kegiatan belajar, keterarahan kegiatan secara logis dan sistematis. Sudjana yang dikutip oleh Trianto (2009: 172) menyatakan, ada lima tahapan yang ditempuh dalam melaksanakan pembelajaran inkuiri, yaitu: a) merumuskan masalah untuk dipecahkan oleh siswa; b) menetapkkan jawaban sementara atau lebih dikenal dengan istilah hipotesis atau permasalahan; c) mencari informasi, data, dan fakta yang diperlukan untuk menjawab hipotesis atau permasalahan; d) menarik kesimpulan jawaban atau generalisasi; dan e) menarik kesimpulan.

Beberapa keunggulan model inkuiri adalah a) membantu peserta didik untuk mengembangkan kesiapan, serta penguasaan keterampilan dalam proses kognitif; b) siswa memperoleh pengetahuan secara individual sehingga dapat dimengerti dan mengendap dalam pikirannya; c) dapat membangkitkan motivasi dan gairah belajar siswa untuk belajar lebih giat lagi; d) memberikan peluang untuk berkembang dan maju sesuai dengan minat masing-masing; e) memperkuat dan menambah kepercayaan pada diri sendiri dengan proses menemukan sendiri karena pembelajaran berpusat pada peserta didik dengan peran guru yang sangat terbatas (Hanafiah dan Suhana, 2012: 78). Namun model inkuiri juga memiliki kelemahan. Beberapa kelemahan model inkuiri yaitu a) siswa harus memiliki kesiapan dan kematangan mental, siswa harus berani dan berkeinginan untuk mengetahui keadaan sekitarnya dengan baik; b) keadaan kelas jumlah siswanya banyak maka model ini tidak akan mencapai hasil yang memuaskan; c) guru dan siswa sudah sangat terbiasa dengan pembelajaran gaya lama maka model ini akan mengecewakan; d) ada kritik, bahwa proses dalam model ini terlalu mementingkan proses pengertian saja, kurang memperhatikan perkembangan sikap dan keterampilan bagi siswa (Hanafiah dan Suhana, 2012: 79).

Beberapa hasil penelitian yang relevan yaitu penelitian yang dilakukan oleh Sitorus, Hasrudin dan Edi (2017) dengan judul The Influence of Inquiry Learning Model on Student's Scientific Attitudes in Ecosystem Topic at MTs. Daarul Hikmah Sei Alim (Islamic Junior High School) Asahan. Tujuan penelitian ini untuk mengetahui pengaruh model pembelajaran Inquiry terhadap sikap ilmiah siswa dalam ekosistem di MTs Daarul hikmah Sei Alim Asahan. Hasil penelitian menunjukkan ada pengaruh pada sikap ilmiah siswa yang diajarkan oleh model pembelajaran inkuiri terbimbing (rerata 77,60), secara signifikan lebih tinggi dari yang model inkuiri bebas dimodifikasi (rerata 63,80) dan model pembelajaran konvensional (rerata 48,27). Penelitian yang dilakukan oleh Safitri dan Budhi (2016) dengan judul pengaruh model pembelajaran inkuiri terhadap hasil belajar IPA ditinjau dari kemandirian belajar siswa. Peneltian ini bertujuan untuk mengetahui pengaruh model pembelajaran inkuiri terhadap hasil belajar IPA ditinjau dari kemandirian belajar siswa. Hasil penelitian ini yaitu ada pengaruh model pembelajaran inkuiri terhadap hasil belajar IPA siswa kelas VIII SMP Negeri 4 Wonosari tahun pelajaran 2016/2017 ditinjau dari kemandirian belajar siswa.

Berdasarkan latar belakang di atas, dilakukan penelitian dengan judul efektivitas model pembelajaran inkuiri terhadap hasil belajar siswa kelas IV SDN 27 Tegineneng. Tujuan dari penelitian ini adalah untuk mengetahui efektif atau tidaknya model pembelajaran inkuiri terhadap hasil belajar siswa kelas IV SDN 27 Tegineneng.

\section{Metode}

Penelitian ini dilakukan di SDN 27 Tegineneng pada tahun pelajaran 2019/2020. Metode yang digunakan dalam penelitian ini adalah metode penelitian eksperimen semu (Quasi experiment). Desain yang digunakan adalah one group pretest and posttest design. Menurut Sugiyono (2012: 110) one group pretest and posttest design adalah suatu teknik untuk mengetahui efek sebelum dan sesudah pemberian perlakuan. Populasi dalam penelitian ini adalah seluruh siswa kelas IV SDN 27 Tegineneng. Sedangkan sampel penelitian ini berjumlah 20 siswa kelas IV SDN 27 Tegineneng.

Penelitian ini menggunakan teknik analisis data dengan uji Wilcoxon yaitu dengan mencari perbedaan mean pretes dan postes. Analisis ini digunakan untuk mengetahui keefektifan model pembelajaran inkuiri terhadap hasil belajar siswa. Karena subjek penelitian kurang dari 25, maka distribusi datanya dianggap tidak normal (Sudjana, 2002: 104) dan data yang diperoleh merupakan data ordinal, maka statistik yang digunakan adalah nonparametrik (Sugiyono, 2012: 213) dengan 
menggunakan Wilcoxon Matched Pairs Test. Penelitian ini akan menguji pretes dan postes. Dengan demikian peneliti dapat melihat perbedaan nilai antara pretes dan postes melalui uji wilcoxon ini. Dalam pelaksanaan uji Wilcoxon untuk menganalisis kedua data yang berpasangan tersebut dilakukan dengan menggunakan analisis uji melalui program SPSS versi16.

\section{Hasil dan Pembahasan}

Penelitian ini untuk mengetahui efektivitas model inkuiri dalam meningkatkan hasil belajar siswa kelas IV SDN 27 Tegineneng pada tema 1 dan sub tema 3. Sebelum dilakukan penelitian, peneliti bersama guru berdiskusi untuk mencari solusi atas permasalahan yang dihadapi, diantaranya kurang aktif siswa dalam mengikuti pembelajaran sehingga dalam pembelajaran terkesan monoton, hanya guru yang menjelaskan materi namun tidak ada upaya dari siswa untuk menambah rasa ingin tahu dan meningkatkan keaktifan siswa di kelas. Berdasarkan hal tersebut, peneliti mencari alternatif model pembelajaran dengan menerapkan model pembelajaran inkuiri.

Pada penelitian dilakukan pretes untuk mengetahui sejauh mana konsep awal siswa dan setelah dilakukan postes. Pretes dan postes digunakan untuk mengetahui apakah model inkuiri efektif meningkatkan hasil belajar siswa kelas IV SDN 27 Tegineneng. Hasil pretes siswa dapat dilihat pada tabel 2 berikut:

Tabel 2. Hasil Pretes Siswa

\begin{tabular}{lll}
\hline No. & Jumlah Siswa & Rata-Rata Pretes \\
\hline 1. & 20 & 68,15 \\
\hline
\end{tabular}

Selanjutnya siswa diberi perlakuan dengan model pembelajaran inkuiri. Setelah materi sub tema 3 selesai diajarkan, dilakukan postes dengan data hasil postes di bawah ini:

Tabel 3. Hasil Postes Siswa

\begin{tabular}{lll}
\hline No. & Jumlah Siswa & Rata-Rata Postes \\
\hline 1. & 20 & 85,25 \\
\hline
\end{tabular}

Setelah diketahui hasil pretes dan postes, kemudian data dianalisis dengan menggunakan uji wilcoxon. Data hasil uji dapat dilihat pada tabel 4 di bawah ini:

Tabel 4. Wilcoxon Signed Rank Test

\begin{tabular}{crrr}
\hline & N & Mean Rank & \multicolumn{2}{c}{ Sum of Rank } \\
\hline Postes-Pretes Negative Ranks & $0^{\text {a }}$ & 0,00 & 0,00 \\
Positive Ranks & $20^{\mathrm{b}}$ & 10,50 & 210,00 \\
Ties & $0^{\mathrm{c}}$ & & \\
Total & 20 & & \\
\hline
\end{tabular}

Keterangan:

a. Postes < pretes

b.Postes $>$ pretes

c. Postes $=$ pretes

Tabel 5. Hasil Test Statistics Wilcoxon Signed Rank Test

\begin{tabular}{lr}
\hline \multicolumn{2}{c}{ Postes - Pretes } \\
\hline Z & $-3,922 \mathrm{a}$ \\
Asymp. Sig. (2-tailed) &, 000 \\
\hline
\end{tabular}

Berdasarkan data di atas, dapat diketahui bahwa Asymp.Sig. (2-tailed) adalah 0.000. Karena 0,00 lebih kecil dari 0,05, maka dapat disimpulkan bahwa model pembelajaran inkuiri efektif meningkatkan hasil belajar siswa kelas IV SDN 27 Tegineneng.

Keefektifan model pembelajaran inkuiri tidak lepas dari peran aktif siswa dalam proses pembelajaran. Materi pelajaran tidak diberikan secara langsung, namun peran siswa dalam model ini 
adalah mencari dan menemukan sendiri materi pelajaran, sedangkan guru berperan sebagai fasilitator dan pembimbing siswa untuk belajar. Lima tahapan yang ditempuh dalam melaksanakan pembelajaran inkuiri, yaitu: a) merumuskan masalah untuk dipecahkan oleh siswa; b) menetapkkan jawaban sementara atau lebih dikenal dengan istilah hipotesis atau permasalahan; c) mencari informasi, data, dan fakta yang diperlukan untuk menjawab hipotesis atau permasalahan; d) menarik kesimpulan jawaban atau generalisasi; dan e) menarik kesimpulan (Trianto, 2009). Model pembelajaran inkuiri menempatkan siswa sebagai subyek dalam proses pembelajaran sehingga siswa berperan untuk menemukan sendiri inti dari materi pelajaran melalui pengalaman yang konkrit sesuai objek yang telah dilihatnya dalam pengamatan.

Pengalaman tersebut memberikan wawasan, dan pemahaman yang sulit dipaparkan melalui pembelajaran dengan pembelajaran biasa. Sedangkan melalui kegiatan diskusi, siswa dapat membahas hasil pengamatan dan memecahkan masalah bersama teman satu kelompok. Kegiatan diskusi dan presentasi akan menciptakan suasana yang kondusif, karena belajar dengan teman akan memudahkan untuk saling bertukar pendapat sesuai dengan pengalaman yang didapat dalam pengamatan. Hasil penelitian ini sesui dengan pendapat Sanjaya (2006: 194) yang menyatakan bahwa model pembelajaran inkuiri merupakan rangkaian kegiatan pembelajaran yang menekankan pada proses berpikir untuk mencari dan menemukan sendiri jawaban dari suatu masalah yang dipertanyakan.

Selain itu, hasil penelitian ini juga didukung oleh beberapa penelitian diantaranya penelitian yang dilakukan Kritianto (2019), hasil penelitian menunjukkan bahwa penerapan model pembelajaran inkuiri dapat meningkatkan berpikir kritis dan hasil belajar siswa dalam pembelajaran IPA kelas IV SD. Penelitian yang dilakukan oleh Arifuddin (2018), hasil penelitian menunjukkan bahwa terdapat pengaruh yang signifikan antara penggunaan model pembelajaran inkuiri terhadap kemampuan pemecahan masalah matematika siswa pada materi pecahan di kelas IV MI Hidayatus Shibyan. Penelitian yang dilakukan oleh Munandar (2019), hasil penelitian menunjukkan bahwa pembelajaran inkuiri melalui praktikum berbasis lesson study sangat efektif dalam meningkatkan penguasaan konsep sistem respirasi dan aktivitas mahasiswa pada saat proses pembelajaran.

\section{Simpulan dan saran}

Berdasarkan penelitian dan pembahasan dalam penelitian ini dapat disimpulkan bahwa model pembelajaran inkuiri efektif dalam meningkatkan hasil belajar siswa kelas IV SDN 27 Tegineneng. Hal ini dibuktikan dari hasil Uji Wilcoxon bahwa Asymp.Sig.(2-tailed) adalah $0.000<0.05$.

Saran yang dapat diajukan adalah sebagai berikut: 1) Saran untuk guru yaitu pembelajran dengan menggunakan model pembelajaran inkuiri dapat dilaksanakan dalam proses pembelajaran sebagai variasi mengajar sehingga tidak monoton dalam pembelajaran. 2) Model pembelajaran inkuiri terbukti dapat meningkatkan hasil belajar siswa sehingga model pembelajaran inkuiri direkomendasikan untuk terus dikembangkan agar siswa tertarik dan termotivasi. Khususnya untuk mengajar mata pelajaran yang memerlukan variasi mengajar yang bukan hanya sekedar ceramah.

\section{Daftar Rujukan}

Abdullah Sani, R. (2013). Inovasi pembelajaran. Jakarta: Bumi Aksara.

Arifuddin, A., Alfiani, D. A., \& Hidayati, S. (2018). Pengaruh Model Pembelajaran Inkuiri Terhadap Kemampuan Pemecahan Masalah Matematika Siswa Kelas IV Madrasah Ibtidaiyah. JURNAL PENDIDIKAN GURU MI, 5(2), 2442-5133, 261-274.

Dimyati dan Mudjiono. (2013). Belajar dan Pembelajaran. Jakarta: Rineka Cipta.

Hanafiah dan Suhana. (2012). Konsep Strategi Pembelajaran. Bandung: PT Refika Aditama.

Iskandar, Agung. (2012). Panduan Penelitian Tindakan Kelas bagi Guru. Jakarta: Bestari.

Jihad, Abdul dan Haris.(2010). Evaluasi Pembelajaran. Yogyakarta: Multi Pressindo.

Kristianto, Y. (2019). PENERAPAN MODEL PEMBELAJARAN INKUIRI UNTUK MENINGKATKAN BERPIKIR KRITIS DAN HASIL BELAJAR SISWA DALAM PEMBELAJARAN IPA KELAS IV SD.e- Jurnal Mitra Pendidikan (JMP Online), 3(11), 1428-1443.

Munandar, R. R., Sutjihati, S., \& Irpan, A. M. (2019). EFEKTIVITAS MODEL PEMBELAJARAN INKUIRI MELALUI PRAKTIKUM BERBASIS LESSON STUDY TERHADAP PENGUASAAN KONSEP SISTEM RESPIRASI. PEDAGONAL/JURNAL ILMIAH PENDIDIKAN, 3(2), 10-17. 
Safitri, S. R., \& Budhi, W. (2017). Pengaruh model pembelajaran inkuiri terhadap hasil belajar IPA ditinjau dari kemandirian belajar siswa. Natural: Jurnal Ilmiah Pendidikan IPA, 4(2), 34-40.

Sanjaya, Wina. (2006). Strategi Pembelajaran. Jakarta: Kencana Prenada Media Group.

Sardiman, A.M. (2014). Interaksi dan Motivasi Belajar Mengajar. Jakarta: Rajawali Pers.

Sitorus, H. H., Hasruddin,. \& Edi, S. (2017). The Influence of Inquiry Learning Model on Student's Scientific Attitudes in Ecosystem Topic at MTs. Daarul Hikmah Sei Alim (Islamic Junior High School) Asahan. International Journal of Humanities Social Sciences and Education (IJHSSE), 4(11), 170-175.

Sudjana. (2002). Metode Statistika. Bandung; Tarsito.

Sugiyono. (2012). Metode Penelitian Kuantitatif Kualitatif dan R\&D. Bandung: Alfabeta.

Trianto. (2009). Mendesain model pembelajaran inovatif-progresif. Jakarta: Kencana Prenada Media Group.

Yudhawati, Ratna.,Haryanto, Dani. (2011). Teori-teori Dasar Psikologi Pendidikan. Jakarta: PT.Prestasi Pustakarya. 